\title{
II SIMPÓSIO DE ARQUEOLOGIA DA REGIÃO SUDESTE
}

O Museu de Arqueologia e Etnologia organizou, sob a coordenação da Profa. Dra. Maria Cristina Mineiro Scatamacchia, o II Simpósio de $\mathrm{Ar}$ queologia da Região Sudeste, dando continuidade à prática de reunir os arqueólogos da região iniciada com o primeiro simpósio realizado no Rio de Janeiro em 1986. Foi organizado levando-se em conta a necessidade de discutir problemas teóricos, conceitos e métodos, e fazer um balanço do estado das pesquisas.

A busca de equivalência das informações resgatadas a partir dos vários projetos que estão sendo desenvolvidos na região, significa uma importante contribuição para o entendimento da ocupação pré-colonial da região, período selecionado como parâmetro para as discussões.

Procuramos fugir do esquema tradicional baseado em comunicações formais, o que não significa que estamos menosprezando este procedimento. Quizemos apenas privilegiar as discussões em torno de questões que foram consideradas relevantes para a região.

A reunião foi realizada nos dias 5, 6 e 7 de abril de 1995, no Auditório do Instituto Oceanográfico da USP.

As discusões foram organizadas sob a forma de mesas temáticas, para as quais foram convidados arqueológos com experiência de diferentes instituições: especialistas que pudessem responder aos vários enfoques e questões pré-determinadas. Foram convidados 10 arqueológos que atuam na região sudeste. O Presidente da Sociedade de Arqueologia Brasileira-SAB e dois ex-presidentes, representando a região norte e a sul foram convidados para abrir os trabalhos científicos com uma palestra.

Cada coordenador de mesa, escolhido entre os pesquisadores do MAE, formulou questões sobre os temas envolvidos, que foram enviados aos participantes para que, em conjunto, fossem estabelecidos os itens que direcionariam as discussões.

O Simpósio foi realizado de acordo com a seguinte programação:

$$
1^{\circ} \mathrm{dia}
$$

Mesa de Abertura:

Magnífico Reitor da USP, Prof. Dr. Flávio Fava de Moraes Pró-Reitor de Extensão e Cultura, Prof. Dr. Jacques Marcovitch
Diretor do MAE, Prof. Dr. Adilson Avansi de Abreu

Presidente da Sociedade de Arqueologia Brasileira, Prof. Dr. Arno Kern

Coordenadora do evento, Profa. Dra. Maria Cristina Mineiro Scatamacchia

Palestra do Prof. Dr. Pedro I. Schmitz: Continuidade e Mudança no litoral de Santa Catarina.

Mesa I - Continuidade da ocupação do litoral sudeste por grupos coletores-pescadores.

Questōes:

- O sambaqui e a diferenciação de outros sítios compostos por conchas.

- Morfologia dos sítios de grupos coletores-pescadores.

- Origem monogênica e poligênica dos construtores de sambaquis.

- Problema da migração e extinção das populações que construíram sambaquis.

- Nomadismo e semi-nomadismo entre os construtores de sambaquis.

- Problemas de cronologia, datas e métodos de datação.

- As fases culturais estabelecidas para os sítios de coletorespescadores.

Coordenação: Profa. Dra. Dorath P. Uchôa. Prof. Dr. Levy Figuti.

Participantes: Profa. Dra. Maria Dulce Gaspar, RJ Profa. Dra. Lina Kneip, RJ

Prof. Dr. Ondemar Dias, RJ Prof. Celso Perota, ES

Mesa II - Continuidade da ocupação do litoral sudeste por grupos horticultores.

Questões:

- A aplicação do conceito de Formativo: definição do processo de produção de alimentos.

- Horticultores ou agricultores incipientes: problema de terminologia ou conceitual?

- Identificação das tradições ceramistas.

- Antigüidade dos grupos ceramistas.

- Morfologia dos sítios dos grupos ceramistas.

Coordenação: Profa. Dra. Maria Cristina M. Scatamacchia

Participantes: Profa. Dra. Lina Kneip, RJ

Profa. Dra. Lilia Cheuiche, RJ

Prof. Dr. Ondemar Dias, RJ

Prof. Celso Perota, ES

$$
2^{\circ} \mathrm{dia}
$$

Palestra do Prof. Dr. Arno Kern: Antecedentes indígenas: problemáticas teórico-metodológicas das sínteses sobre pré-história regional.

Mesa I - A ocupação do interior da região sudeste pelos caçadores-coletores.

Questões: 
- São Paulo como área de transição das tradições meridionais e do planalto central.

- Utilização dos estudos de padrões de assentamento.

- Variabilidade das indústrias líticas.

Coordenação: Profa. Marisa C. Afonso

Participantes: Profa. Dra. Maria da Conceição Beltrão, RJ Prof. Dr. Ondemar Dias, RJ

Prof. Dr. Andrá Prous, MG

Prof. Dr. José Luis de Morais, SP

Prof. Paulo A. De Blaisis, SP

Prof. Paulo Seda, RJ

Mesa II - A ocupação do interior da região sudeste pelos grupos horticultores.

Questões:

- Metodologia e técnicas de campo aplicáveis em sítios de horticultores ceramistas.

- Relações intra-sítio.

- Contexto regional e ambiental das ocupações ceramistas.

Coordenação: Prof. Dr. José Luiz de Morais

Participantes: Prof. Dr. André Prous, MG Profa. Dra. Marcia A. Alves, SP

Profa. Eliana T. Carvalho

$$
3^{\circ} \text { dia }
$$

Palestra da Profa. Dra. Gabriela Martin: Arqueologia do Nordeste: análise dos principais projetos de pesquisa.

Mesa I - Manifestações da arte rupestre na região sudeste. Questões:

-Critérios para a definição das tradições, sub-tradições e estilos. - Terminologia para a arte rupestre: tentativa de uniformizar a nomenclatura utilizada pelas diferentes equipes.
- Análise das figuras: distribuição espacial, técnicas, associações, temas e cronologias.

- Correlação da arte rupestre com contexto arqueológico.

- Símbolos, signos e eventos.

Coordenação: Prof. Paulo A. De Blasis

Participantes: Profa. Dra. Maria da Conceição Beltrão, RJ Prof. Dr. André Prous, MG

Prof. Paulo Seda

Mesa II - Discussão Final.

Participantes: Profa. Dra. Dorath P. Uchôa

Prof. Dr. Levy Figuti

Profa. Dra. Maria Cristina M. Scatamacchia

Profa. Marisa C. Afonso

Prof. Paulo A. De Blasis

A realização deste simpósio possibilitou uma visão geral dos principais problemas e dificuldades que estão enfrentando os arqueólogos que atuam na área. Mostrou também a necessidade da realização de encontros desta natureza, pois a prática de debate e discussão é que vai auxiliar na orientação das pesquisas futuras.

Como resultados concretos, além da positiva troca de informações entre colegas, houve a formulação de propostas visando a uniformização terminológica e a de coleta de amostras.

Assim, a reunião periódica de profissionais para a realização de um balanço das pesquisas e dos conhecimentos adquiridos é fundamental para o desenvolvimento e orientação da pesquisa arqueológica em qualquer região.

\section{Maria Cristina Mineiro Scatamacchia*}

